\title{
Music as the Medicine of Trauma among Refugees in Arizona
}

\author{
Bernard Austin Kigunda Muriithi ${ }^{1 \text { * }}$ \\ 1 A.T. Still University of Health Sciences, USA \\ *bernardmuriithi@atsu.edu \\ Received: 25 September 2019 Accepted: 28 April 2020 Published: 1 July 2020 \\ Editor: Susan Hadley Reviewers: Marisol Norris, Ezekiel Bautista
}

\begin{abstract}
This paper presents outcomes of a phenomenological study conducted to explore the lived experience of refugee musicians. Purposive and snowball sampling methods were used to identify six musicians who performed in the cities of Phoenix and Tucson and had been involved in music prior to entering the United States. The primary data gathering method was structured and unstructured interviews, but observations were made for the musicians who performed in public events during the study period. Audio and video recordings were made and photographs taken during these performances. Study outcomes show that the musicians have persisted in music performance as their primary method of healing trauma and negative emotions. Traumatic experience resulted in their fleeing from their homes and seeking refuge in other countries. After being resettled in the United States, they continue to suffer from the experience of loss, need to adapt and change, and struggle with trauma and negative emotions. Music is their method of healing trauma and facilitating integration. Music produces healing through 1) like a painkiller, enabling them to forget problems that result in distress, 2) being their means to communicate a message of hope, and 3 ) enabling integration, thus reducing isolation and loneliness.
\end{abstract}

Keywords: African immigrants, healing, forced displacement, community integration, community music therapy

\section{Introduction}

According to the United Nations Refugee Agency, 70.8 million people were forcibly displaced worldwide in 2018 (United Nations High Commissioner for Refugees [UNHCR], 2019). Of those, 25.9 million were refugees, 41.3 million were internally displaced, and 3.5 million were asylum seekers (UNHCR, 2019). In 2017, 80,000 refugees and asylum seekers, mostly from the Democratic Republic of Congo, Iraq, and Syria, were admitted to the United States (US) (UNHCR, 2019). Generally, survivors of forced displacement have a history of emotional turmoil or trauma because they witnessed serious atrocities, such as murder, rape, and torture. As such, refugees and asylum seekers continue to be affected psychologically in their host countries. In a study 
of refugee students in North Korea, Choi (2010) found avoidance, disgust, loneliness, feelings of loss, and fear were common despite treatment with music therapy. Several studies (Davies, 2009; Saksena \& McMorrow, 2019; Shishehgar et al., 2016) have identified barriers to successful resettlement, including lack of language competence resulting in isolation, limited work and leisure activity due to language and financial challenges, difficulty maintaining habits and routines due to unfamiliarity with the environment, loss of family for practical and emotional support, loss of social connectedness because of differences between the country of origin and the host country, and culture shock.

Although it is widely acknowledged that refugees need access to mental health services (Hynie, 2018), most resettlement policies do not prioritize the health, education, and social wellbeing of refugees (Burbage $\&$ Walker, 2018). This lack of access may be related to low prioritization of mental health in federal and state policies and to the high cost of healthcare in the United States (Papanicolas et al., 2018). The failure to address mental health symptoms among refugees can in turn affect quality of life and productivity of these individuals.

The use of music when serving the mental health needs of refugees has had reported value in refugee camps (Akombo, 2001; Dau \& Sweeney 2007), for individuals with sleep disturbances (Jespersen \& Vuust, 2012), and in community (Felsenstein, 2013; Signorelli \& Bright, 2006) and clinical settings (Choi, 2010; Jespersen \& Vuust, 2012; Jin, 2016; Orth, 2005). Research has also shown the effectiveness of music in dealing with posttraumatic stress disorder among refugees (Beck et al., 2018; Felsenstein, 2013). In one study, the inclusion of refugees in a Swedish choral music performance helped them integrate into their new communities, but more appropriate models of applying music for this purpose are indicated (Quadros \& Vu, 2017). In another report, music therapy aided intercultural exchange and provided opportunities for integration through singing and performing percussive music (Posselt \& Antink, 2016). Despite the cultural (and musical) differences between musicians with refugee and Unites States backgrounds, the readiness and ability to engage both in shared music making activity has value in the overall health and integration of these individuals into a community.

Evidence also suggests that refugees could apply music and dance to manage their own stress and deal with trauma. The 2007 award-winning documentary God Grew Tired of Us shows how the Lost Boys of Sudan experienced deep emotional wounds and trauma after the death of their parents and escape to the Kakuma refugee camp in Kenya (Dau \& Sweeney, 2007). Despite the horrific situation, they still experienced moments of relaxation at the refugee camp because music performance and dance helped them, for a moment, to forget their trauma and sense of despair. These musical experiences are not strictly music therapy as defined in the West, and there are ongoing discussions about suitable terminologies for this ontological reality. Stige (2002) proposed "folk music therapy" whereas Kigunda (2003) described similar practices as "some form of music therapy" which could benefit from premeditated processing and refinement to (metaphorically) become "canned music therapy" (Kigunda, 2004). Music was not the only factor supporting the Lost Boys of Sudan, but it helped change despair into hope in this vulnerable population. The therapeutic impact of music here is similar to that of professional music therapy. As such, music therapists and other clinicians can learn much from studying how refugees use music to address trauma. This can only improve the approaches used to address refugee health and wellness.

As music therapists and other professionals advance research into clinical approaches that may provide refugees necessary relief from mental health problems, there is value in understanding the shared and individual experiences of refugees as a means of determining possible solutions. One way to approach this problem is to find out how refugees already use music in their lives. Thus, by understanding their lived experience in relation to the daily application of music, their health-related issues and other challenges can be better addressed. Although experimental studies provide important evidence for approaches that serve the needs of refugees and are generalizable to other populations, qualitative research studies are necessary to characterize experiences 
that are multidimensional, complex, subjective, immeasurable, and more nuanced. Researchers investigating the application of music in healing require a better awareness of the realities that change between peoples, contexts, times, and cultures. Further, understanding the lived experience of refugees allows music therapists and other professionals to develop needed assessment methods and treatments. For instance, better assessment tools are needed that consider cross-cultural understanding of posttraumatic stress disorder and other mental health problems affecting refugees (Eklund et al., 2018; Gadeberg et al., 2017). Approaches to treatment must also be informed by the refugee's view of the world and concept of healing. The utility of music, in particular, must be directed by their understanding of music and how it supports recovery from trauma, anxiety, and depression. Most importantly, we should be aware that what refugees need may not necessarily be found in the theories and approaches designed for Western clients.

The aim of the current study was to determine how music performance produces health-related benefits perceived as therapeutic and supportive of health, growth, and wellness of refugees, their families, and communities. To gain an in-depth understanding of the lived experiences of refugee musicians, a phenomenological design was used. This design allows the voices of refugees to be clearly understood as they report what matters to them in a richly engaging manner. As a result, music therapists, other professionals, and persons living in host countries can be better informed to create models that facilitate the use of music and talent for the benefit of the refugees and the communities in which they are resettled.

\section{Methods}

\section{Phenomenological Design}

The current study used a phenomenological design because the phenomenon under investigation had objective and subjective elements that required methodological flexibility. Phenomenology allows for mixing of methods, triangulation of different kinds and sources of data, and descriptive and interpretive approaches. Thus, the researcher can examine the phenomenon from the point of view of participants while collecting a variety of data for analysis. Phenomenology is a strong approach to understand the human experience without the limitations of objective or subjective methods.

Phenomenology begins with epoche, also called bracketing, where the phenomenon is considered without bias (Gallagher, 2012; Kigunda, 2012). The next step is phenomenological reduction, where the time and context of the phenomenon is considered with an awareness that the participants' lived experience may change with changes in context or environment. Finally, eidetic reduction is used to imagine all possible variations of the phenomenon without changing the essence of the phenomenon under examination (Gallagher, 2012). This process enables researchers to narrow down a phenomenon to what is essential to an experience or phenomenon (Gallagher, 2012; Kigunda, 2012).

\section{Participants}

The current study used purposive and snowball sampling to identify six study participants. Initial contact was made when the researcher met refugee musicians at community events, such as World Refugee Day celebrations in 2018 and 2019 and World Bazaar PHX in 2019, where refugees from around the world perform to entertain guests. Other contacts were obtained through refugee resettlement agencies. Those invited to participate in the study were artists involved in music making before and after being resettled in the US. The number of years that participants had been in the United States ranged from one year to over 10 years, and all were admitted to the United States as refugees. Participants worked in other industries and did not primarily make music to earn their living, but they all verbalized that as an unfulfilled desire. Four of the selected musicians (Furaha, Baraka, DJ Grin, and MC Joel) were originally from 
the Democratic Republic of Congo (DRC) and lived as refugees in Uganda before being resettled in the US. Two of these Congolese musicians (Furaha and Baraka) were from the same family and included a mother and one of her adult sons who often performed and recorded music as a family. One of the remaining participants was originally from Burundi (Don Brighter) and was a refugee in Tanzania before being resettled in the US. The last participant was from the Kachin tribe (Zau), and he had started making music in Myanmar before being resettled in the United States with his family. Only participants who could communicate in English or Kiswahili were included in the study although other participants were considered if an interpreter could be found.

\section{Data Collection}

After participants were identified, the aims of the study and the roles of participants were explained to them, when necessary with interpretation into Kiswahili. The consent forms described the study and their role in detail, including the need to commit to at least 75 minutes of an initial face-to-face interview (structured and unstructured) and subsequent phone interviews or conversations as needed to clarify any unclear statements. Participants additionally consented to observation, photographs, and video recordings whenever they performed music in the community. All but one of the participants provided links to their YouTube channels. Although this medium included valuable video material for analysis, it was not required for participation in the study. None of the participants was concerned about privacy. Instead, they preferred to be identified by their own stage names and saw their participation in the study as part of being recognized as musicians. They also considered the extra exposure would be beneficial for their musical careers and increase their popularity. They were lastly asked to sign Institutional Review Board-approved consent forms.

\section{Structured and Unstructured Interviews}

The primary method of gathering data was structured and unstructured interviews. The following five guiding questions were considered when preparing the interview questions: (a) Did participants perceive that music performance contributed to their subjective wellbeing and to the wellbeing of their families and communities? Why or why not? (b) What function(s) did music serve (or was perceived to serve) in the health and wellness of participants, their families, and communities? (c) What environmental barriers to their music making did the participants encounter? (d) What steps had participants taken to mitigate the impact of perceived barriers in their performance? and (e) What did participants perceive as possible solutions to the challenges they faced regarding their music performance? From these, the primary investigator created a questionnaire of 13 open-ended questions that was used in all structured interviews. If issues arose from these initial questions, follow-up questions were used to clarify answers.

At the end of the structured interview, participants were asked to provide any other details about their experiences that they thought were pertinent for the current study. As a result, unstructured interviews immediately followed the structured interview. The unstructured interviews were flexible, and their content varied depending on what the primary investigator (interviewer) and participant wanted clarified. The primary investigator is proficient in Kiswahili and translated some of the questions from English to Kiswahili during interviews to ensure that participants with limited English proficiency were understood. Notes were taken during interviews, and all structured and unstructured interviews were audio recorded. The interviews were transcribed verbatim and used in subsequent analyses.

\section{YouTube Channels}

Five of the six participants had YouTube channels where they posted their music and had followers. They provided links to these channels on the initial interview day and 
continued to post new videos during the study period. The collection of older and newer music videos on these channels provided data to assess changes in their music performance over time.

\section{Observations}

Some of the participants were invited performers at events organized collaboratively by state and non-governmental organizations. Participating agencies include Arizona Refugee Resettlement, Catholic Charities, International Rescue Committee, Lutheran Social Services and a number of other smaller agencies. The participants were generous in communicating whenever these events were scheduled, and they were invited as music performers. The investigator attended many of these events, made video recordings, and took photographs. Some of the events were World Refugee Day 2019, World Bazaar PHX, and Phoenix Unknown to name a few.

\section{Analysis}

To increase reliability and objectivity, triangulation was used when analyzing the interviews, video and audio recordings, and observations so that the resulting themes would characterize the lived experience of music performance and healing for the study participants. The information conveyed by participants during the separate interviews was compared for similarities and differences. Those themes were then compared with the themes from the text of songs obtained from studio recordings and live community performances. Essential overall themes were obtained through this process.

It should be noted that the study investigator was instrumental in planning, gathering, analyzing, and presenting the data. While the goal for the study was to describe the lived experiences of the participants, the investigator determined what to include, the organization of the content, and the degree of in-depth description. Another consideration when interpreting study results is that the phenomenological approach relied heavily on the ability of the investigator to correctly and adequately describe, interpret, classify, and present essential elements of the study. For instance, a different investigator may have interpreted the data differently, selected different areas of focus, or presented the results in a different way. The investigator sought to ensure that the study focus was on the views shared by participants and not on interpretations of the investigator.

\section{Results and Discussion}

\section{Background Considerations}

Without careful consideration of individual life stories, only limited understanding of the lived experience of study participants is possible. However, full accounts of the participants' life stories are outside the scope of the current article. Therefore, selected facts are presented for better comprehension of study results. Understandably, all participants had an acute, deeply entrenched awareness of their personal backgrounds because of the traumatic experiences that led them to flee their home countries, leaving behind property and loved ones. The refugee camps in which they lived afterwards, both in countries near their home countries and in the US, presented different kinds of challenges to overall living and to music performance.

Furaha is the mother of eight children. In the DRC, she led her church choir, performed music during church services, and recorded gospel songs. She escaped to Uganda with her children after witnessing murders and rape in her country. Once in Uganda, she adapted to the Kampala environment and continued to perform gospel music for the new urban audience. She recorded music with her children, produced videos for sale, and was a dressmaker to supplement her income. She was eventually resettled in the United States with all her children, where she continues to make music, produce videos, and perform at community events (Figure 1). She reported that her music was 


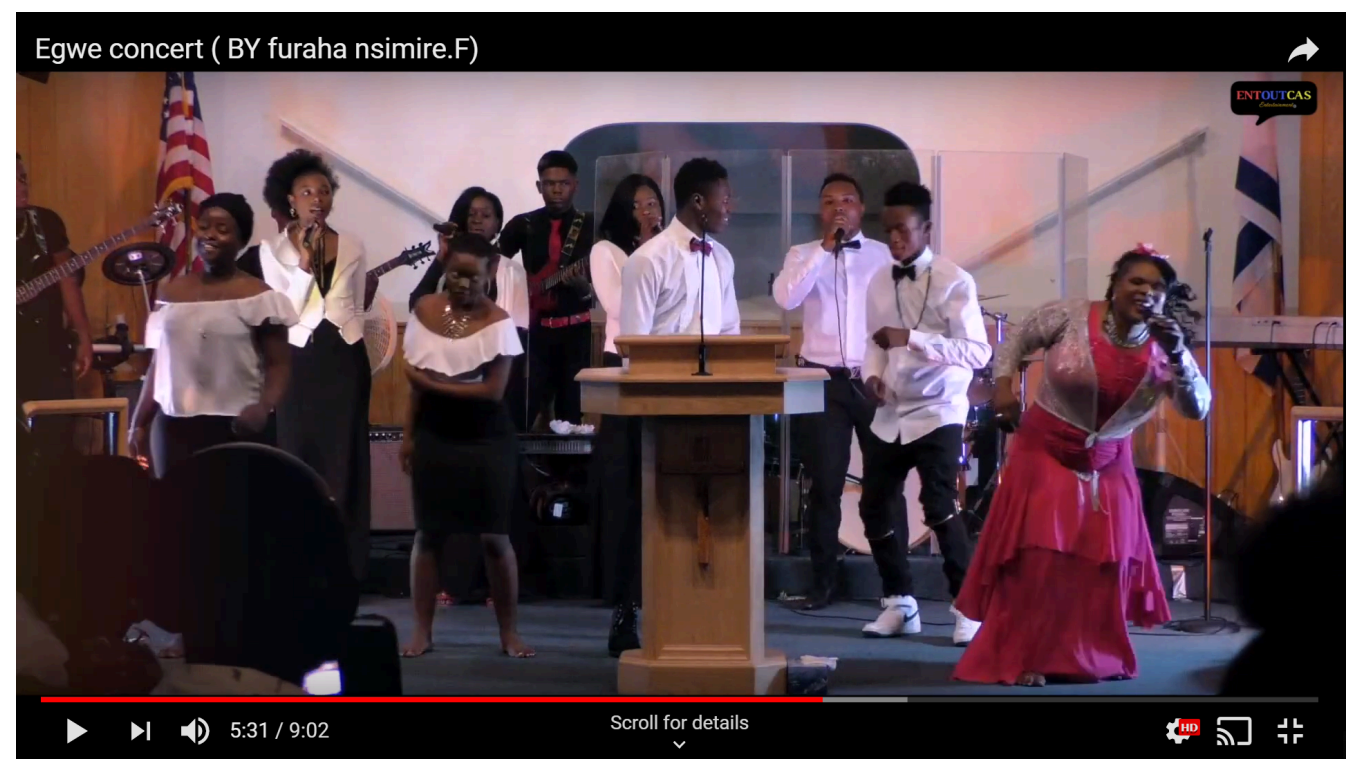

Figure 1

Furaha (right) and her family and friends performing Igwe at a church concert in Phoenix (Furaha Nsimire.F, n.d.). There is a studio-recorded version of Igwe (recorded in Kampala, Uganda) posted in another of her YouTube channels (Furaha Nsimire, n.d.).

much more appreciated in the DRC and Uganda. She attributed the lack of comparable interest in her (gospel) music in the United States to a general lack of interest in music among United States' residents, although this is disputable if expressed this way.

Furaha's son Baraka began performing music in Kampala, Uganda. Because the family lacked basic things, he felt obligated to perform whatever kind of music his audience wanted (Baraka, personal interview, June 20, 2019). He performed some "world music" (by which he meant secular music) against his will to earn a living, and he seemed to carry some guilt from that experience. But Baraka also performed and recorded gospel music with his family, and the videos were sold to supplement family income. Since coming to the US, he has stopped performing "world music" because he believes the purpose of music is for the glory of God and nothing else. This self-imposed restriction is rooted in his personal beliefs. He believes his resettlement in the United States is God-given gift, and he is unapologetic about confining all music making to church-related activities only (Figure 2). God has blessed him, he said, with a job that pays for his expenses and leaves a little leftover for studio fees whenever he has a song to record.

DJ Grin and MC Joel were taken to a Ugandan refugee camp as children. They lived in Uganda as musicians and were eventually resettled in the United States. They both reported using music to educate, inspire, and entertain refugees at the camp, and some of those songs are posted on their YouTube channels (DJ Grin the peacemaker, n.d.; MC Joel, n.d.). When interviewed, DJ Grin mourned the loss of his media following and his inability to access television and radio in the US. He viewed his resettlement as a "backsliding" in his musical career because he lost the audience he worked hard to garner for himself while in Uganda (DJ Grin, personal interview, April 12, 2019). Like Furaha and Baraka, DJ Grin and MC Joel have difficulty getting the kind of audience they had in Uganda. Despite these drawbacks, they have continued to seek opportunities to perform music, adapt their styles, and integrate themselves and their families into communities in the United States.

Don Brighter was born in Burundi but moved to Tanzania with family to flee violence in his home country. He recalled enjoying Zulu music that was played over and over on a radio station. He defined music as a language that communicated "without even having to say a word that somebody can understand" (Don Brighter, personal interview, April 27, 2019). Don later left Tanzania, was resettled in the United States, 


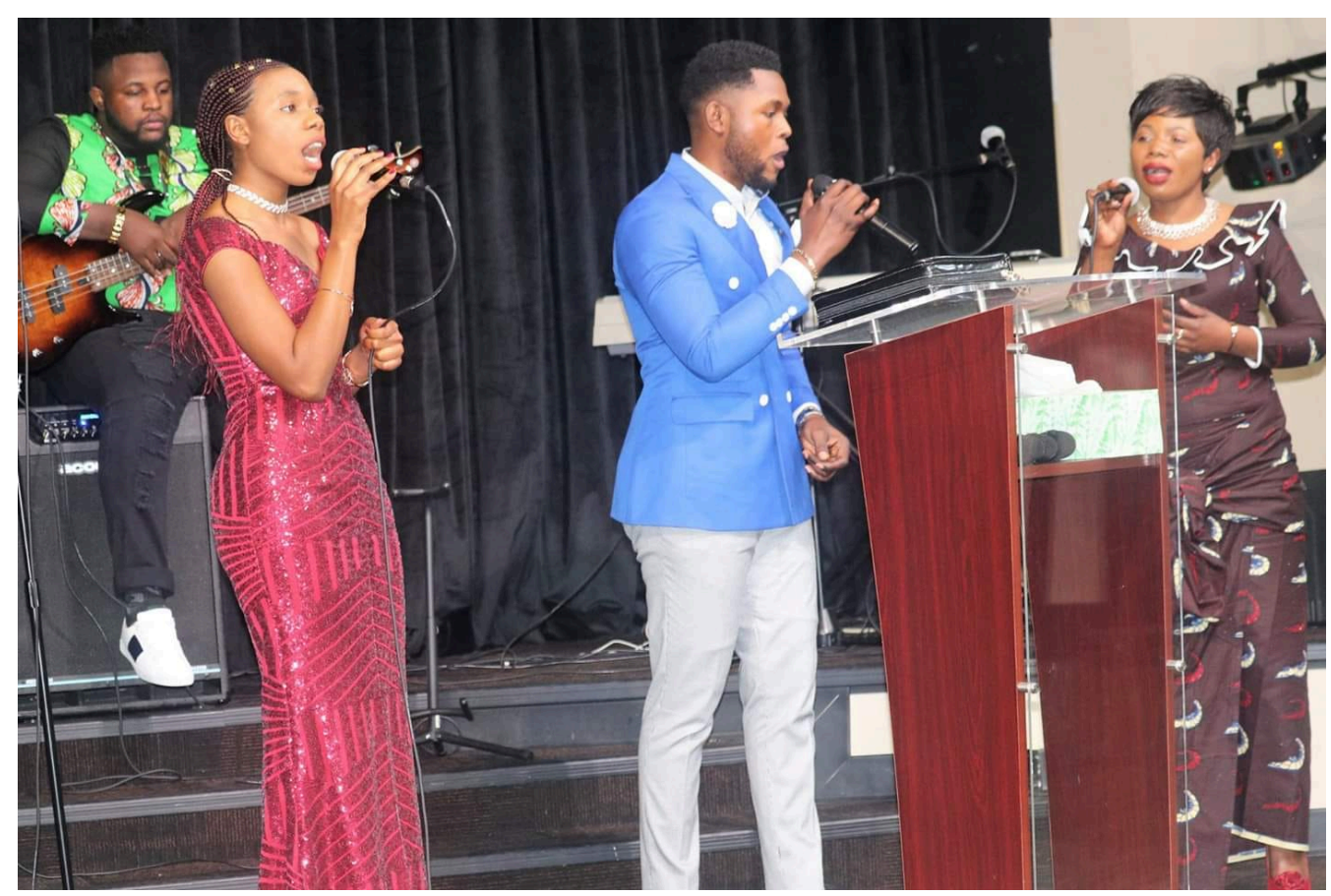

Figure 2

Baraka (2nd right) leads other performers at his local church in Phoenix, AZ.

and recently graduated with a criminal justice degree. Initially after resettlement, he worked for Catholic Charities (an agency that helps with refugee resettlement), but he eventually left that job to focus on his music. Don recognizes that Americans appreciate songs in English even though he thinks the language should not matter, so he writes some songs in English. He also writes songs in Kiswahili and Kirundi or, as in his song Fire Fire (Figure 3), mixes languages, which is a common practice among Tanzanian youth (Englert, 2008). Don's music is similar to other Bongo Flava artists who fuse material from a variety of genres, including hip-hop, rumba, reggae, soukous, and Western styles (Reuster-Jahn, 2014; Sanga, 2013,, 2011; Stroeken, 2005). He also indicated that he performs Afropop and rhythm and blues. For Don, history tells him that music is a language because, as a child, he "understood" Zulu music without knowing the Zulu language. Experience has taught him that openness to style and language change is wise for the audience in the United States. Like other study participants, he stands between Africa and the West and identifies as a citizen of the United States and as an African.

Zau was the only participant from outside of Africa. He was born and raised in Myanmar but escaped the violence there and was later resettled in the US. He learned to play guitar and compose music from a private tutor in Myanmar. Zau devotes his time to gospel music and is a pastor of the Myanmar Christian Church, a community of people from Myanmar and Nepal who worship together on Sundays. While recognizing that Asian and American music types are entirely different, he described his style as modern rock even though his music does not closely resemble American rock. Like Don Brighter, Zau believes that music is a language, but he also recognized that his limited English proficiency, along with stylistic differences between Asia and the West, impact his music performance in the United States. However, he has an audience at his church that understands his language and appreciates his music performance style (Zau, personal communication, April 30, 2019). Therefore, he is not presently targeting outside American audiences. 


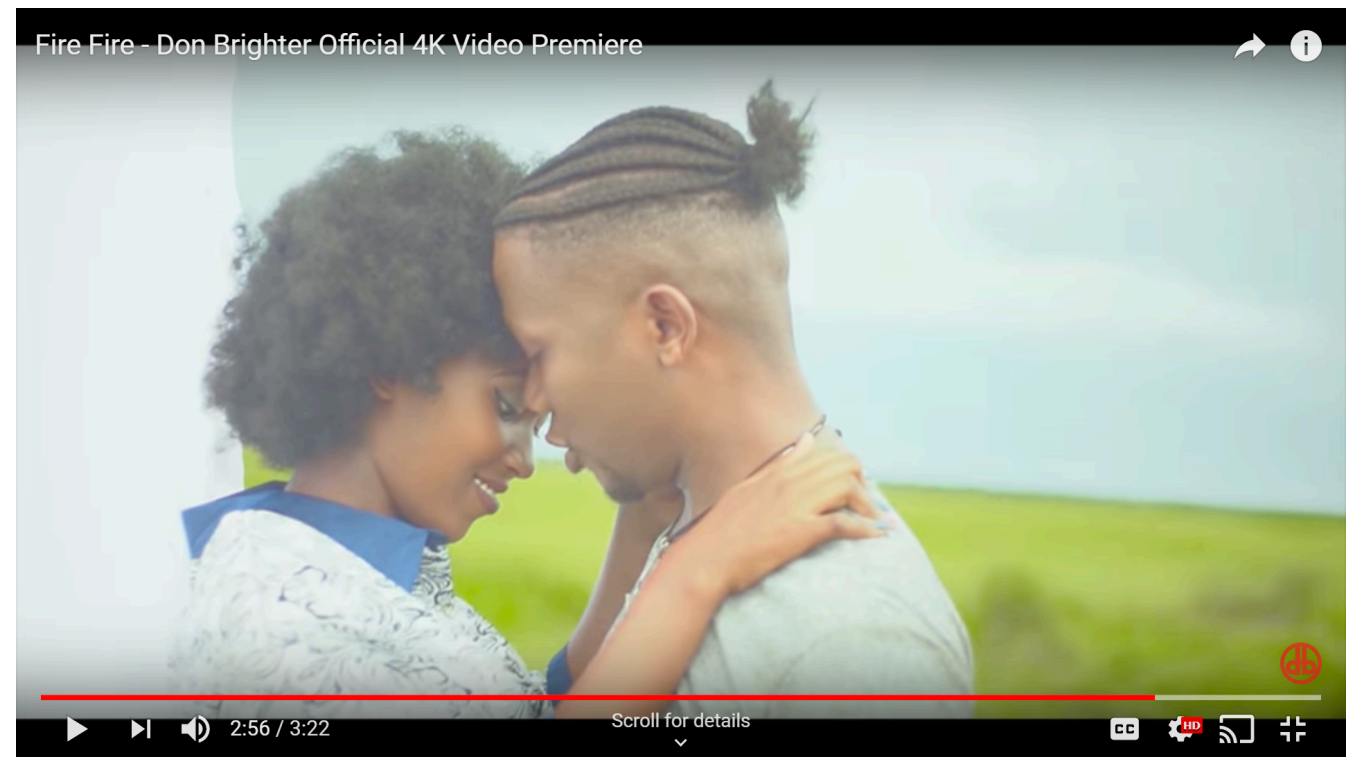

Figure 3

Don Brighter (right) performs a romantic piece Fire Fire with a female companion. Available on YouTube (Don Brighter, n.d.).

\section{A Sense of Loss}

One of the most salient observations from the interviews was that participants experienced serious personal loss because of displacement, flight, and resettlement. For example, the loss of Furaha's home in the DRC was quickly followed by the need to leave her home country to protect her children. This decision resulted in the loss of contact with many close relatives and friends. From a music making standpoint, she had to acculturate to the new environment in Kampala, Uganda, before she could begin to attract a new audience with revised music, some of which is posted on her YouTube channel (Furaha Nsimire, n.d.). In 2017, she was lucky to be resettled in the United States, which increased her safety and ability to work and earn her living. However, the United States environment did not provide reliable enough performance opportunities to generate an income from music performance. She accepted a job as a caregiver, but she and her children, including Baraka, perform music at community events and at their local church. Their performances in the United States are not presently aimed at generating income; they are more for psychological wellness, community service, and evangelization. For examples of Furaha's songs after resettlement in the United States, visit her YouTube channel (Furaha Nsimire.F, n.d.). As another example of loss, shortly after the first interview for the current study, DJ Grin lost his mother and was unable to return to the DRC to attend her funeral because of safety, legal, and economic barriers.

Participants also felt a sense of loss from their inability to take advantage of developed skills to their economic and social benefit after the change of sociocultural environment because of resettlement. Both DJ Grin and MC Joel lost their substantial and growing audience in Uganda after resettlement, but they are starting to establish new audiences in the United States. DJ Grin verbalized the shared feeling that Americans do not appreciate refugee talent when he stated, "you are only known as a refugee, that's it" (DJ Grin, personal interview, April 12, 2019). He wants to also be known as a musician, a father, a leader of a youth talent group, and a husband, not simply as a refugee. Don Brighter recognized there was less interest in his variety of music, i.e., Bongo Flava, Afropop, and rhythm and blues, which was compounded by the need to write songs in English. Like other study participants, Don was searching for a middle ground that embraced his background and the United States cultural, linguistic, or musical elements. On the other hand, Zau was less concerned about fitting into the broader United States environment and was instead focused on serving the Myanmar 
Christian Church in Phoenix, Arizona. But he recognized this focus as a barrier to community integration which limited his ability to exploit his full potential in the United States.

The above examples of the sense of loss are not comprehensive because the experience of loss differed greatly between participants in terms of what they missed the most. Some participants grieved over the loved ones in their home countries or in refugee camps outside of the United States that they missed. Also, there were variable degrees of grief about their musical talents that were less appreciated in the United States than elsewhere because of stylistic, linguistic, and cultural reasons related to the meaning and role of religion. Some felt a loss of time they would normally dedicate to music making that was instead taken up by having to work in other industries to earn a living. As such, they had limited time for music. Additionally, five participants wished they could use the less expensive recording studios outside the US, which met their needs and enabled them produce better quality recordings. Whatever the loss experienced by participants, they all felt a strong sense of having lost something of substantial emotional, economic, or cultural value.

\section{Adaptation and Change}

It is difficult to appreciate the determination of the participants to maintain their music performance activity without looking at how they adapted to changing environments. Rather than give up music performance, they changed to better respond to new cultural contexts. Furaha and Baraka started their music making in the DRC, but then in Uganda they performed new songs in Kiganda and Kiswahili before they left Africa. They are now trying to find their place in the American environment. Looking at their YouTube channel (Furaha Nsimire, n.d.) shows that Furaha and Baraka have experimented with all kinds of genres, such as hip-hop-styled Christian music, which is very different from the gospel music from Eastern Africa they appear to be most familiar with. They have sung in nearly half a dozen languages between the DRC, Uganda, and the United States. Similarly, DJ Grin, MC Joel, Don Brighter, and Zau have had to deal with change and adaptation. They have changed styles and languages based on their location but have always found a way to integrate African or Asian and Western idioms. Looking at their YouTube channels (Brighter, n.d.; DJ Grin the peacemaker, n.d.; MC Joel, n.d.), one sees a collection of musical styles that include popular gospel, Congolese rumba, Bongo Flava, rhythm and blues, Afropop, and hip-hop. There was a clear distinction between participants who mostly restricted themselves to gospel music, such as Furaha, Baraka, MC Joel, and Zau, and those who were more open to performing secular music, such as DJ Grin and Don Brighter. Openness to secular music, along with certain methods of choreography, may attract American audiences because the music is like styles and song themes already popular with youth in the United States. The change of style and language therefore characterized the experience of music between changing sociocultural contexts.

\section{Benefits of Music Performance}

The fortitude to sustain music performance with low economic return (if not financial loss) must have underlying motivators. In general, study interviews suggested the key justification was related to the healing benefits of music. To fully comprehend these benefits, the root causes of healing that have a direct relationship with music experience must be examined. Since participants of the current study are refugees, they share the same experience of displacement as other displaced persons. Therefore, their use of music at refugee camps before resettlement and in the United States after resettlement is driven by the need to ameliorate serious health and environmental challenges.

One way to use music to promote healing is to create a sense of hope in oneself and others. Doing so creates the belief, somewhat paradoxically, that things are currently all right and that they will be better in the future. Study participants appeared to consider music as the essential vehicle for conveying inexplicable messages to the depths 


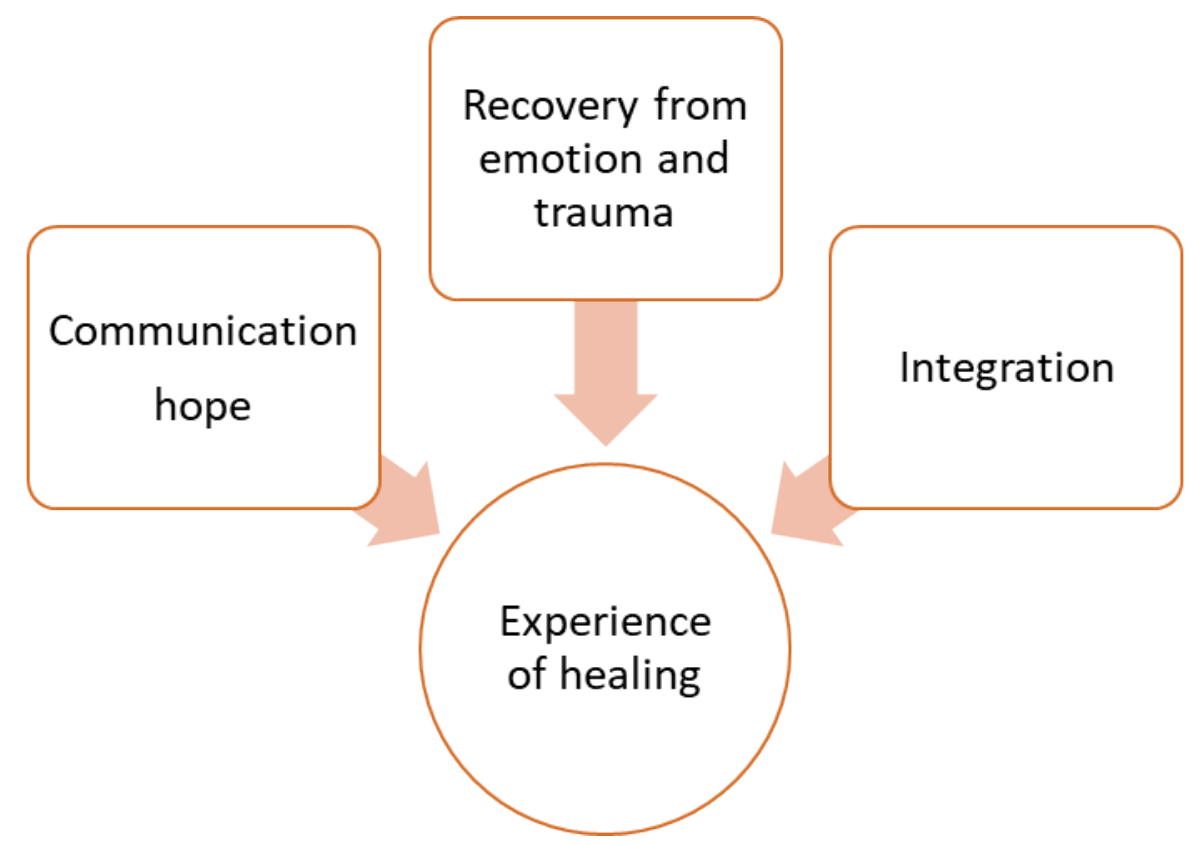

Figure 4

Healing benefits of music performance.

of the human psyche, thus ameliorating the experience of trauma and emotional turmoil. Additionally, music created opportunities for community integration and enabled further healing from problems associated with isolation and loneliness. As such, the interrelated elements of recovery from trauma and emotion, communication, and community integration create the overall experience of healing from music performance (Figure 4).

Recovery and healing. This element is the primary reason for continuing to perform music when there are few economic benefits from the activity. Although all participants expressed in some way that music heals trauma and negative emotions, they expressed that belief differently. DJ Grin probably expressed it best when he defined music thusly: "music is life...music is unity...music is the medicine of trauma" (DJ Grin, personal interview, April 12, 2019). This understanding of the healing benefits of music has practical implications. For instance, DJ Grin has sung songs to inspire, unite, and bring people with different backgrounds together; his song One People is a good example of this and is available on his YouTube channel (DJ Grin the peacemaker, n.d.). Don Brighter added another insight. He indicated that music does not take away one's problems, but like a "painkiller" it helps to take away pain so that a person can "maybe forget about the problem even when the problem is not solved" (Don Brighter, personal interview, April 27, 2019).

The trauma experienced by study participants was outside their control, but their resolve to use music to counter the effects of that trauma and other emotional problems showed that they perceived healing as being within their control. They believed that trauma could be ameliorated, if not completely removed, by making music. Although they were not directly questioned about whether they had considered psychological counseling, no participant stated, or even implied, that professional counseling had a place in their recovery. Perhaps they were unaware of counseling as an alternative or they had a better and cheaper method that worked for them. Through the healing power of music, DJ Grin went from traumatic childhood experiences, as indicated by his statement that "I was not born to see dead bodies," to the present, where people wonder "why are you always smiling?" (DJ Grin, personal interview, April 12, 2019). The other participants indicated that music had healed their traumas and negative emotions in similar ways. They all had memories of horrific things that happened in their home countries, memories of loved ones left behind, and the experience of lacking ba- 


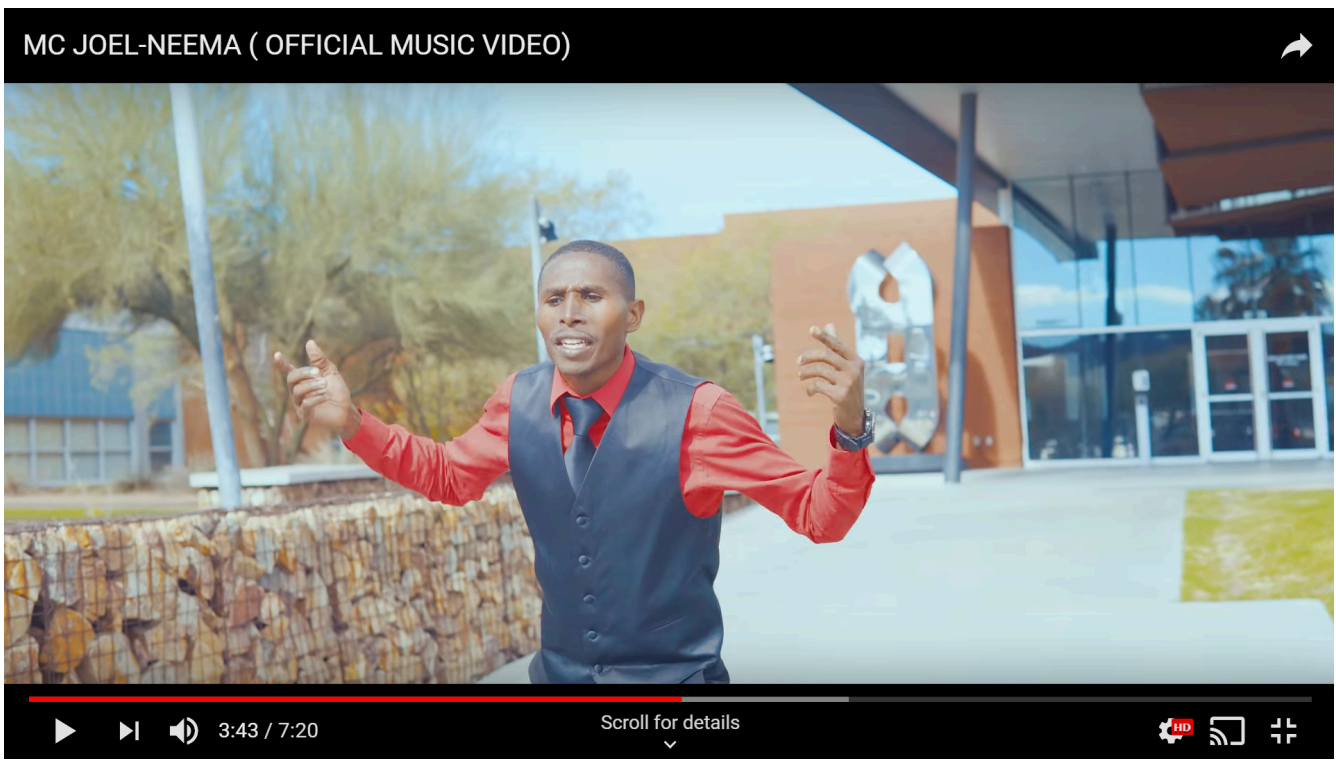

Figure 5

MC Joel performing Neema which means "grace" (of God). There is a video recording of this song in his YouTube channel (MC Joel, n.d.).

sic things for survival. Any of these experiences can evoke fear or anxiety when not actively managed with care. Music is such a companion for decreasing emotional turmoil or sustaining hope in serious challenges that "it is hard to imagine life without music" (DJ Grin, personal interview, April 12, 2019).

Communication. Study participants used their music to communicate to targeted groups, including themselves. Don Brighter spoke most eloquently about customizing messages to match a situation. He indicated that the purpose of music is to communicate, but unlike speech, he saw music as a more potent means to communicate everything from political ideas to romantic ideas to deeper messages that no words were able to express. To him any experience of music that generated or restored wellness was a sign that a message, incomprehensible as it may be, was communicated. Often, it happens with words (song texts), but sometimes it happens without words. MC Joel also used music to regulate emotions. For instance, he sometimes used headphones to filter everything else out, so he could direct all his attention to music. MC Joel's song Neema, available on his YouTube channel (MC Joel, n.d.), captures his philosophy about how to respond to adversity. The grace of God, he says in Neema, is enough no matter what the problem is (Figure 5). By that, he means grace is enough to endure any kind of pain. The song also stresses that it is not by anyone's intelligence, power, or wealth but by the grace of God that that things are as they are; therefore, it is always important to be grateful to God.

MC Joel and DJ Grin used music to educate, inspire, encourage, and instill hope in other refugees at the camp in Uganda. They did this as a charity to help their fellow refugees remain hopeful, positive, and dedicated to whatever they had to do to survive. In the song Amkeni, available on his YouTube channel (MC Joel, n.d.), MC Joel tells his audience, the refugees at the camp in Uganda, that there was no place for idleness and sloth, and he urged them to wake up and work hard. Furaha, Baraka, and Zau have also inspired their audiences in the DRC, Uganda, Myanmar, and the United States, respectively, but their inspiration is rooted in Christian teachings. In the song Igwe that Furaha performs with Baraka and her other children, they tell their audience that God has all power and rhetorically ask, "Father you can break all tents, why should I fear?" (Furaha Nsimire, n.d.). Furaha, Baraka, Zau, and to some degree MC Joel limit themselves to writing gospel songs. Despite differences in beliefs, study participants used music to convey messages of hope, peace, and solidarity among all peoples. Further, 


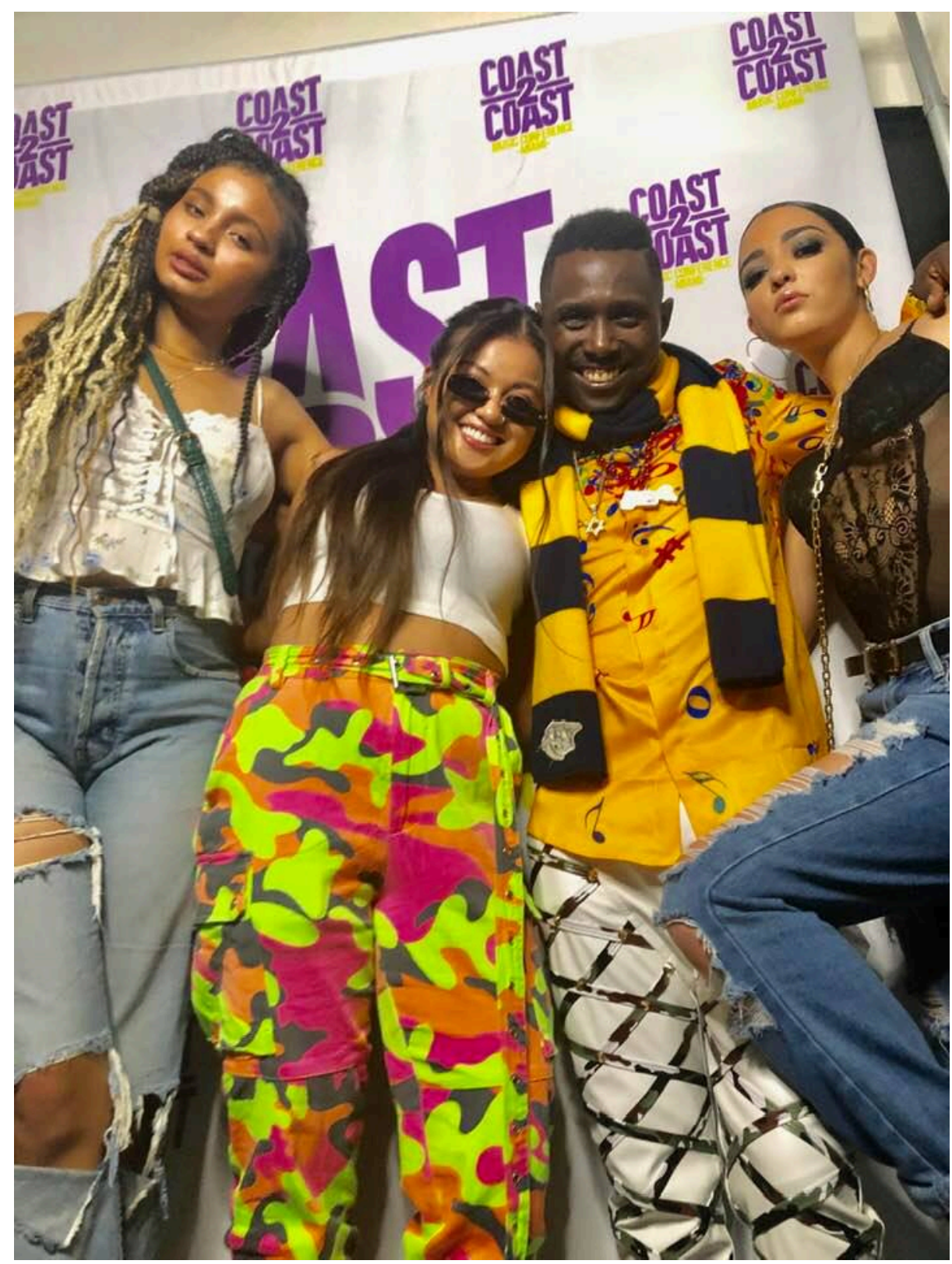

Figure 6

DJ Grin (second from right) with fellow artists after performing at the Coast2Coast Miami competitions on August 31, 2019. DJ Grin travels widely in the United States to perform music in community gatherings.

they were conscious of potential differences in race and culture among their audiences and hoped for a more united, loving, and peaceful world.

Integration. As the participants moved from nation to nation, the performance of music appeared to be the means of connecting with residents in the new places where they settled. However, this connection was not always successful because language, cultural, and economic factors limited or slowed down the process. Therefore, the participants used music to share their values and promote what they regarded as valuable and true. They also used the opportunities arising from their skills to integrate better into communities and to meet new friends. For instance, Baraka felt that the performance of music earned him respect among his new acquaintances who were from diverse backgrounds.

During the study, DJ Grin and MC Joel were participants in large musical talent competitions (see www.coast2coastlive.com). At those competitions, they met other artists and competed for sponsorships. After winning second place at his local Coast2Coast audition, DJ Grin was sponsored to perform at the Coast2Coast Miami 
competitions; his performance is available on his Facebook Live account (DJ Grin the peacemaker, 2019). This competition also enabled him to meet other artists (Figure 6).

For participants of the current study, the pattern of engagement with the community has the potential to popularize their music and open new avenues for growth of their talents. It also has the potential to facilitate a return to music careers as their primary source of income. The performances of participants create avenues to learn, connect with fellow artists, and find possible future collaborators. For instance, Zau has used his music skills to promote his evangelistic ministry at the Myanmar Christian Church, which includes immigrants from Myanmar and Nepal as well as people from other parts of the world, including the United States. All study participants have been performers in local community events in the United States, and it is their performance of music that has created these contacts and a new audience. Although this audience may be limited when compared with their African or Asian audiences, it still promotes their integration and possible popularization in the United States' communities. Ultimately, their music has decreased their isolation and increased opportunities for success in the United States.

\section{Conclusion}

For the six participants of the current study, there was a clear indication that the performance of music was very meaningful when dealing with trauma, anxiety, and other negative emotions. Performing music helped them deal with trauma in three ways. First, music had the effect of calming serious negative emotions and memories of traumatic experiences. Many can relate to the use of music to regulate emotions and enhance wellness because it is a healthy way to engage the mind and distract from detrimental thoughts and memories. Second, music was used by the participants to communicate a message of hope with themselves and others during a time of doubt, fear, and anxiety. The value of these messages is related to both content and context. This distinction is important because only those who have traumatic memories and anxieties from similar lived experiences can appreciate the participants' messages in a comparable way. Furthermore, musically communicating to inspire others was seen as a charitable activity by participants. They considered it as an offered gift of musical counsel and a "treat" for the community. This outlook had the benefit of creating a sense of accomplishment and value in the participants and in others. Third, music helped them deal with trauma by providing opportunities for integration into their new communities in refugee camps or in the US. Because of their experiences, participants are at a high risk of marginalization and isolation. The necessary departure from their home countries resulted in the loss of numerous social ties and usually required them to learn a new language and embrace a new cultural context through the process of assimilation.

The study suggests that music performance can be very helpful in facilitating the integration of refugees into communities in the United States. Music can be the key for opening new avenues for collaboration in artistic ventures. Furthermore, we see gifted musicians among refugees in the United States who can be instrumental in relieving stress associated with traumatic experience shared by many refugees. Therapists, social workers, case managers, and other professionals working in communities where these individuals are resettled should consider ways to use creative talents in individual or group interventions to promote wellness, decrease isolation, and enhance community participation. Resettlement agencies should also consider developing more programs that use the creative talents of refugees to improve health, economic status, and integration outcomes.

\section{Acknowledgements}

The author would like to acknowledge the following people for their assistance. My wife Jennifer Muriithi, founder and director of Tapestry (an organization that serves refugees), was a partner in the data collection and was very helpful with obtaining 
contacts from her work with refugees in the Phoenix area. Linda Materu, research assistant and occupational therapy doctoral student at A.T. Still University, transcribed all interviews verbatim and translated interviews done in Kiswahili into English. Deborah Goggin from research support at A.T. Still University edited original manuscript and suggested modifications for improvement.

\section{About the author}

Bernard Austin Kigunda Muriithi is an assistant professor of occupational therapy at A.T. Still University, Mesa, Arizona. He is a Kenyan musicologist whose $\mathrm{PhD}$ research, completed at Otto-von-Guericke University of Magdeburg - Germany, focused on the relationship between music and health in multiple Kenyan contexts (including traditional rituals, Christian rituals, and Nairobi street musicians). He presently works as an occupational therapist, educator, and interdisciplinary researcher in the United States.

\section{References}

Akombo, D. O. (2001). Reporting on music therapy in Kenya. Nordic Journal of Music Therapy, 9(1), 60-63, https://doi.org/10.1080/08098130009477987.

Beck, B. D., Lund, S. T., Sogaard, U., Simonsen, E., Tellier, T. C., Cordtz, T. O., Laier, G. H., \& Moe, T. (2018). Music therapy versus treatment as usual for refugees diagnosed with posttraumatic stress disorder (PTSD): Study protocol for a randomized controlled trial. Trials, 19(1), 301, https://doi.org/10.1186/s13063-018-2662-z.

Brighter, D. (n.d.). Home [YouTube channel]. https://www.youtube.com/user/MrDgboyz/ featured.

Burbage, M. L., \& Walker, D. K. (2018). A call to strengthen mental health supports for refugee children and youth. NAM Perspectives, https://doi.org/10.31478/201808a.

Choi, C. M. H. (2010). A pilot analysis of the psychological themes found during the CARING at Columbia Music Therapy Program with refugee adolescents from North Korea. Journal of Music Therapy, 47(4), 380-407.

Dau, J. B., \& Sweeney, M. S. (2007). God grew tired of us. National Geographic.

Davies, R. (2009). Working with refugees and asylum seekers. In N. Pollard, D. Sakellariou, \& F. Kronenberg (Eds.), A Political Practice of Occupational Therapy (pp. 183-189). Elsevier.

DJ Grin the peacemaker. (2019). Facebook Live. https://www.facebook.com/ DJ\%20Grin.donald.3/videos/737354003373940/.

DJ Grin the peacemaker. (n.d.). Home [YouTube channel]. Retrieved from https://www.youtube.com/channel/UCq9EYsUrtqOdBJCXw9D05xw/featured.

Eklund, K., Rossen, E., Koriakin, T., Chafouleas, S. M., \& Resnick, C. (2018). A systematic review of trauma screening measures for children and adolescents. School Psychology Quarterly, 33(1), 30-43, https://doi.org/10.1037/spq0000244.

Englert, B. (2008). Kuchanganyachanganya: Topic and language choices in Tanzanian youth culture. Journal of African Cultural Studies, 20(1), 45-55, https://doi.org/10.1080/ 13696810802159255.

Felsenstein, R. (2013). From uprooting to replanting: On post-trauma group music therapy for pre-school children. Nordic Journal of Music Therapy, 22(1), 69-85, https://doi.org/10.1080/ 08098131.2012.667824.

Gadeberg, A. K., Montgomery, E., Frederiksen, H. W., \& Norredam, M. (2017). Assessing trauma and mental health in refugee children and youth: A systematic review of validated screening and measurement tools. European Journal of Public Health, 27(3), 439-446, https://doi.org/10.1093/eurpub/ckx034.

Gallagher, S. (2012). Phenomenology. Palgrave Macmillan.

Hynie, M. (2018). The social determinants of refugee mental health in the post-migration context: A critical review. Canadian Journal of Psychiatry, 63(5), 297-303, https://doi.org/ 10.1177/0706743717746666. 
Jespersen, K. V., \& Vuust, P. (2012). The effect of relaxation music listening on sleep quality in traumatized refugees: A pilot study. Journal of Music Therapy, 49(2), 205-229, https://doi.org/10.1093/jmt/49.2.205.

Jin, S. (2016). Giving and caining: Experiences of three music facilitators on working and musicking with asylum seekers in Australia. Australian Journal of Music Therapy, 27, 13-26.

Kigunda, B. (2003). Music Therapy: A Therapeutic Force Remains Anonymous in Kenya. Voices: A World Forum for Music Therapy, 3(3), https://doi.org/10.15845/voices.v3i3.131.

Kigunda, B. (2004). Music Therapy Canning and the Healing Rituals of Catholic Charismatics in Kenya. Voices: A World Forum for Music Therapy, 4(3), https://doi.org/10.15845/ voices.v4i3.186.

Kigunda, M. (2012). Music and health in Kenya: Sound, spirituality and altered consciousness juxtaposed with emotions. Akademiker Verlag.

MC Joel. (n.d.). Home [YouTube channel]. Retrieved from https://www.youtube.com/ channel/UCttyiGmSunILqEK59wBzG9Q/featured.

Nsimire, F. (n.d.). Home [YouTube channel]. Retrieved from https://www.youtube.com/ channel/UCYfQY-ouJIuozhQJbJi_ATg.

Orth, J. (2005). Music therapy with traumatized refugees in a clinical setting. Voices: A World Forum for Music Therapy, 5(2), https://doi.org/10.15845/voices.v5i2.227.

Papanicolas, L. R., \& Jha, A. K. (2018). Health care spending in the United States and other high-income countries. JAMA, 319(10), 1024-1039, https://doi.org/10.1001/ jama.2018.1150.

Posselt, T., \& Antink, M. T. H. (2016). The sound of lost homes: music therapy with refugees in Germany. Nordic Journal of Music Therapy, 25, https://doi.org/10.1080/ 08098131.2016.1180121.

Quadros, A., \& Vu, K. T. (2017). At home, song, and fika: Portraits of Swedish choral initiatives amidst the refugee crisis. International Journal of Inclusive Education, 21(11), https://doi.org/10.1080/13603116.2017.1350319.

Reuster-Jahn, U. (2014). English versus Swahili: Language choice in Bongo Flava as expression of cultural and economic changes in Tanzania. Swahili Forum, 21, 1-21.

Saksena, J., \& McMorrow, S. L. (2019). Through their eyes: A photovoice and interview exploration of integration experiences of Congolese refugee women in Indianapolis. Journal of International Migration and Integration, https://doi.org/10.1007/s12134-019-00672-1.

Sanga, D. (2013). Traditional dances and Bongo Fleva: A study of youth participation in ngoma groups in Tanzania. 20, 67-84.

Sanga, I. (2011). Mzungu Kichaa and the figuring of identity in "Bongo Fleva" in Tanzania. International Review of the Aesthetics and Sociology of Music, 42(1), 189-208.

Shishehgar, S., Gholizadeh, L., DiGiacomo, M., Green, A., \& Davidson, P. M. (2016). Health and socio-cultural experiences of refugee women: An integrative review. Journal of Immigrant and Minority Health, 19(4), 959-973, https://doi.org/10.1007/s10903-016-0379-1.

Signorelli, R., \& Bright, R. (2006, October). From trauma to hope: A music therapy journey with refugees. Paper presented at the Australian Music Therapy Association National Conference, Sydney, Australia.

Stige, B. (2002). Culture-centered music therapy. Barcelona Publishers.

Stroeken, K. (2005). Immunizing strategies: Hip-hop and critique in Tanzania. Africa: Journal of the International African Institute, 75(4), 488-509.

United Nations High Commissioner for Refugees. (2019). Refugee statistics. https://www.unrefugees.org/refugee-facts/statistics/. 